\title{
Interactive Effects of Stress and Aging on Structural Plasticity in the Prefrontal Cortex
}

\author{
Erik B. Bloss, ${ }^{1}$ William G. Janssen, ${ }^{1}$ Bruce S. McEwen, ${ }^{3}$ and John H. Morrison ${ }^{1,2}$ \\ ${ }^{1}$ Fishberg Department of Neuroscience and Kastor Neurobiology of Aging Laboratories, and ${ }^{2}$ Department of Geriatrics and Adult Development, Mount \\ Sinai School of Medicine, New York, New York 10029, and ${ }^{3}$ Laboratory of Neuroendocrinology, Rockefeller University, New York, New York 10021
}

Neuronal networks in the prefrontal cortex mediate the highest levels of cognitive processing and decision making, and the capacity to perform these functions is among the cognitive features most vulnerable to aging. Despite much research, the neurobiological basis of age-related compromised prefrontal function remains elusive. Many investigators have hypothesized that exposure to stress may accelerate cognitive aging, though few studies have directly tested this hypothesis and even fewer have investigated a neuronal basis for such effects. It is known that in young animals, stress causes morphological remodeling of prefrontal pyramidal neurons that is reversible. The present studies sought to determine whether age influences the reversibility of stress-induced morphological plasticity in rat prefrontal neurons. We hypothesized that neocortical structural resilience is compromised in normal aging. To directly test this hypothesis we used a well characterized chronic restraint stress paradigm, with an additional group allowed to recover from the stress paradigm, in 3-, 12-, and 20-month-old male rats. In young animals, stress induced reductions of apical dendritic length and branch number, which were reversed with recovery; in contrast, middle-aged and aged rats failed to show reversible morphological remodeling when subjected to the same stress and recovery paradigm. The data presented here provide evidence that aging is accompanied by selective impairments in long-term neocortical morphological plasticity.

\section{Introduction}

Neuronal networks in the prefrontal cortex (PFC) mediate the highest levels of cognitive processing and decision making, including working memory and flexible use of mental strategies (Miller et al., 2002). The capacity to perform these functions is among the cognitive features most vulnerable to aging in humans (Grady, 2008). Likewise, there is much evidence that animal models ranging from nonhuman primates (NHPs) to rodents also display age-related impairments in PFC-dependent tasks (Gallagher and Rapp, 1997). Animal studies thus provide powerful models to study neurobiological correlates to age-related prefrontal dysfunction.

Our understanding of the neurobiological basis of age-related prefrontal decline remains incomplete. In neurodegenerative disease such as Alzheimer's Disease (AD), neuron death is typically observed: however, stereological investigations have demonstrated that neuron loss is neither inevitable nor sufficient to explain age-related cognitive impairments in the absence of disease (Rapp and Gallagher, 1996; Morrison and Hof, 1997). One hypothesis is that in the absence of neocortical neuron loss, subtle alterations in neocortical plasticity in intact neural circuits drive age-

Received Feb. 11, 2010; accepted March 25, 2010.

This study was supported by Predoctoral Fellowship 1F31AG034794-01A1 from the National Institute on Aging to E.B.B. and by Conte Center Grant MH58911 from the National Institute of Mental Health to B.S.M. and J.H.M. We thank Carine Hamo, Dan Ohm, and Shannon Wadsworth for expert technical assistance, and Drs. Rebecca Shansky and Yuko Hara for critical discussion of the manuscript.

Correspondence should be addressed to Dr. John H. Morrison, Fishberg Department of Neuroscience, Kastor Neurobiology of Aging Laboratories, Mount Sinai School of Medicine, One Gustave L. Levy Place, New York, NY 10029. E-mail: John.morrison@mssm.edu.

DOI:10.1523/JNEUROSCI.0759-10.2010

Copyright $\odot 2010$ the authors $\quad 0270-6474 / 10 / 306726-06 \$ 15.00 / 0$ related cognitive decline (Hof and Morrison, 2004). Previous studies have demonstrated age-related morphological alterations in pyramidal neurons in humans, NHPs, and rodents, which collectively suggest that impairments in structural plasticity play an important role in neocortical aging (Dickstein et al., 2007). On the other hand, many studies have failed to demonstrate structural alterations with age, and it remains unclear whether aging is associated with impairments in structural plasticity (Burke and Barnes, 2006).

One key question in gerontology is how adverse experience over the lifespan can interact with the aging process (Sapolsky, 1999; Lupien et al., 2009). In rodent models, stress has been shown to cause impairments in set-shifting tasks dependent on the medial prefrontal cortex (mPFC), deficits that correlate with morphological changes in prefrontal neurons (Liston et al., 2006). Aged rats are impaired on the same shift in the task while leaving other tasks independent of the mPFC intact (Barense et al., 2002), suggesting that stress and aging may target overlapping prefrontal neuron populations.

Evidence from animals and humans suggest that, at least in younger subjects, these stress-induced behavioral and neuronal changes can be reversed (Radley et al., 2005; Liston et al., 2009). The present study addressed whether aging influences the reversible nature of stress-induced morphological plasticity in $\mathrm{mPFC}$ neurons. We hypothesized that neocortical structural plasticity is compromised with aging: to directly test this hypothesis we used a well characterized chronic restraint stress (CRS) paradigm with an additional group allowed to recover from the stress paradigm in 3-, 12-, and 20-month-old male rats. The data presented here provide evidence that aging is accompanied by selective impairments in long-term neocortical morphological plasticity. 
A

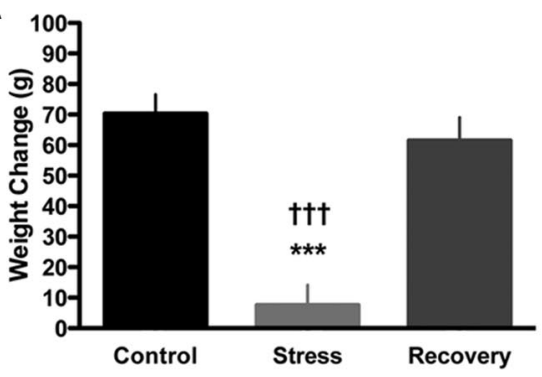

B

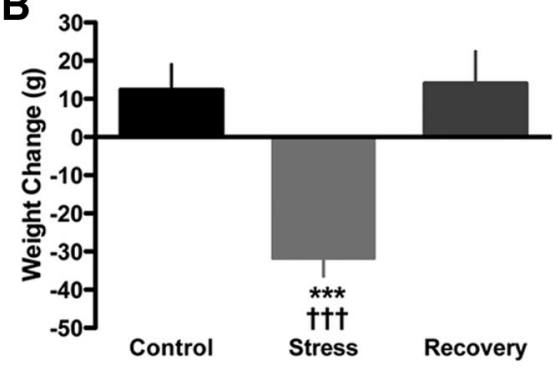

C

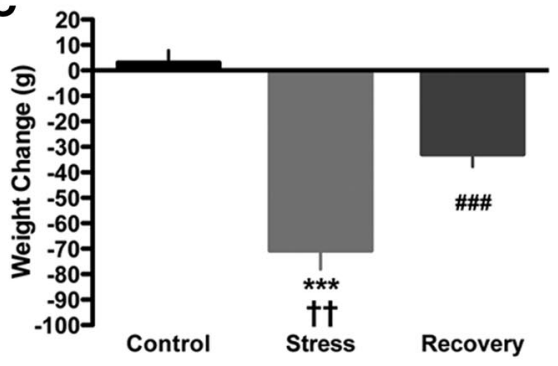

Figure 1. Stress causes body weight alterations at all ages. $\boldsymbol{A}$, In 3-month-old rats, stress reduced weight gain over the course of the paradigm, which normalized with 3 weeks of recovery. $\boldsymbol{B}$, In 12 -month-old rats, stress caused weight loss that normalized with recovery. $\boldsymbol{C}$, In 20 -month-old rats, stress caused robust weight loss that did not normalize with 3 weeks of recovery. ${ }^{* * *} p<0.001$, control versus stress; ${ }^{\dagger \dagger} p<0.005$, stress versus recovery; ${ }^{+\dagger+} p<0.001$, stress versus recovery; ${ }^{\# \# \# ~} p<0.001$, control versus recovery. Data presented represent group mean \pm SEM.

\section{Materials and Methods}

Animals and CRS paradigm. Sixty-nine male Sprague Dawley rats (Harlan) aged 3, 12 and 20 months of age ( $n=21-24$ per age), were housed in clear polycarbonate cages $(45 \times 25 \times 20 \mathrm{~cm})$ with woodchip bedding, kept on a 12:12 h light/dark cycle at $21 \pm 2{ }^{\circ} \mathrm{C}$, and allowed standard rat chow and tap water ad libitum. Rats were weighed every 3 d during the course of the experiment. Rats were allowed 1 week to acclimate to the Rockefeller University vivarium before the onset of the CRS paradigm. CRS entailed placing rats in appropriately sized wire mesh restrainers with rubberized edges at $1000 \mathrm{~h}$ and removed at $1600 \mathrm{~h}$ daily for 21 consecutive days. Recovery consisted of an additional $21 \mathrm{~d}$ in the same vivarium. All experiments were conducted in compliance with the National Institutes of Health Guidelines for the Care and Use of Experimental Animals and approved by the Institutional Animal Care and Use Committee at Mount Sinai School of Medicine and Rockefeller University.

Perfusions and tissue processing. Approximately $24 \mathrm{~h}$ after the last stressor, animals were overdosed using $100 \mathrm{mg} / \mathrm{kg}$ sodium pentobarbital and transcardially perfused with $4 \%$ paraformaldehyde $+0.125 \%$ glutaraldehyde in $0.1 \mathrm{M}$ phosphate buffer, $\mathrm{pH}$ 7.3. The descending aorta was clamped and nonfixed adrenal glands were removed and weighed. Brains were removed, postfixed for $6 \mathrm{~h}$, then cut into $250 \mu \mathrm{m}$ coronal sections using a Vibratome (Leica, VT1000S) encompassing the entire prelimbic (PL) cortex of the mPFC (PL anterior border, $5.16 \mathrm{~mm}$; PL posterior border $2.52 \mathrm{~mm}$ from bregma) according to Paxinos and Watson (2005). Sections for ionophoretic cell loading were stored in $0.1 \mathrm{M}$ PBS at $4^{\circ} \mathrm{C}$ until processing.

Ionophoretic cell loading. Ionophoretic cell loading was performed as described previously (Radley et al., 2006). Approximately 5 sections were available for cell loading encompassing the entire extent of the PL cortex. Neurons in layer III of the PL cortex (see Fig. $2 \mathrm{~A}$ ) were impaled with a micropipette containing 5\% Lucifer yellow (Invitrogen) in distilled water and injected at 1-6 nA for $\sim 5-10 \mathrm{~min}$ to completely fill all distal aspects of the dendritic tree (see Fig. $2 \mathrm{~B}$ ). Slices were washed in PBS, mounted on SuperFrost Plus microscope slides (Fisher), coverslipped with FluoroMount-G (BD Diagnostic Systems), and stored at $4^{\circ} \mathrm{C}$.

Neuronal reconstructions. Neurons were reconstructed in $3 \mathrm{D}$ using a Zeiss Axiophot 2 microscope (Zeiss) equipped with a $40 \times$ objective (Plan-NEO, 1.3 NA), a motorized stage, video camera system, and Neurolucida morphometry software (MBF Bioscience) (see Fig. 2C) by an experimenter blind to the experimental conditions. To be included in the analysis neurons had to exhibit full dendritic trees, in accord with criteria previously published from our laboratory (Radley et al., 2006). Dendritic length data, branch point data, and Sholl analysis were prepared for each neuron with NeuroExplorer software (MBF Bioscience), imported into Microsoft Excel and averaged to obtain a mean for each animal.

Statistical analyses. Statistical analyses were done using GraphPad Prism software. Adrenal glands were normalized to body weight using the following formula: adrenal gland weight $(\mathrm{mg}) /$ body weight $(\mathrm{g}) \times$ 100. Final animal weights were subtracted from initial weights to determine the overall weight change over the course of the experiment. Adrenal and body weight data were analyzed using a one-way ANOVA and
Bonferonni's post hoc tests. Neuronal reconstruction data including apical dendritic length, apical branch points, and basal dendritic length were averaged per animal and analyzed using one-way ANOVA and Bonferroni post hoc tests. Sholl data were analyzed by a two-way mixed-model repeated-measures ANOVA with condition as a between groups factor and radial distance from soma (in $30 \mu \mathrm{m}$ increments) as a within group factor. Differences at individual distances in the Sholl analysis were determined with Bonferroni post hoc tests. For all above statistical tests, $\alpha$ was set at 0.05 . All data presented represent mean \pm SEM.

\section{Results}

\section{CRS-induced changes in body weights and relative adrenal} gland weights

Exposure to daily restraint stress for 3 weeks has been reported to cause reductions in body weight and adrenal gland hypertrophy (Watanabe et al., 1992a; Magariños and McEwen, 1995). We measured these variables to determine whether these CRS effects are similar or different in aging rats. In 3-month-old rats, we corroborated a main effect of condition (i.e., control, stress, or recovery) on weight gain over the course of the paradigm $\left(F_{(2,21)}=\right.$ 24.44, $p<0.0001)$ and a decrease of weight gain in the stress group compared with both control and recovery animals (Fig. $1 A)$. We also found a main effect of condition on adrenal weights $\left(F_{(2,21)}=4.03, p<0.05\right)$, though post hoc tests did not reveal any significant differences between the groups (data not shown). In 12-month-old animals, we found a main effect of condition on weight change $\left(F_{(2,23)}=14.75, p<0.0001\right)$, and weight loss in stress but not recovery animals compared with controls (Fig. $1 B$ ). We found a main effect of condition on adrenal weights $\left(F_{(2,23)}=\right.$ $21.03, p<0.0001)$, and an increase in stress $(p<0.001)$ and recovery $(p<0.01)$ animals compared with control (data not shown). In 20-month-old rats, we found a main effect of condition on weight change $\left(F_{(2,22)}=39.98, p<0.0001\right)$, with decreased weight in stress and recovery groups compared with control, as well as a difference between stress and recovery conditions (Fig. 1C). A main effect of condition on adrenal weights was also found $\left(F_{(2,22)}=\right.$ $8.793, p<0.005)$, with increased adrenal weights in stressed animals compared with controls $(p<0.01)$ (data not shown).

\section{Effects of CRS and recovery on prefrontal apical dendritic morphology across ages \\ Young animals ( 3 months)}

A total of 21 animals ( $n=7$ per condition) had optimal perfusions, and $162 \mathrm{PL}$ neurons were suitable for use for neural reconstructions (range $=5-13$, mean $=7.7$ neurons per animal) (Fig. 2 ). We found a main effect of condition on total apical dendritic length $\left(F_{(2,20)}=54.61, p<0.0001\right)$, and a decrease in stress lengths compared with control and recovery (Fig. $3 A$ ). Similarly, we found a 

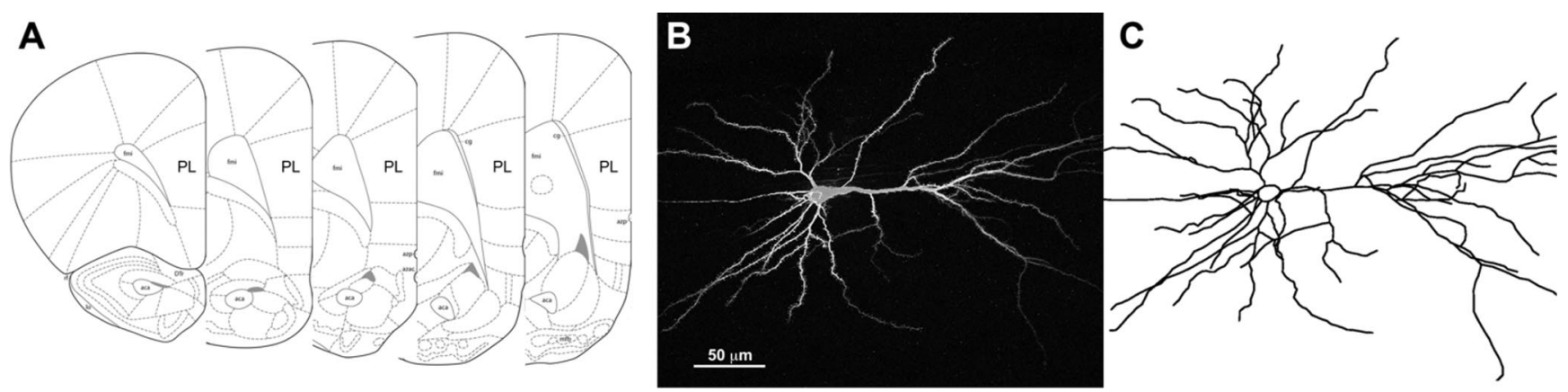

Figure 2. Neuronal reconstructions. A, Anatomical localization of rat PL cortex. Adapted from Paxinos and Watson (2005). B, A deconvolved confocal image of a Lucifer yellow-filled layer III PL pyramidal neuron. C, A manual reconstruction of the same neuron. Pial surface of the PL cortex is to the right.

A

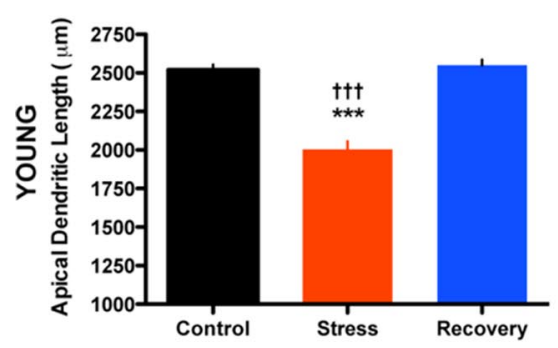

D

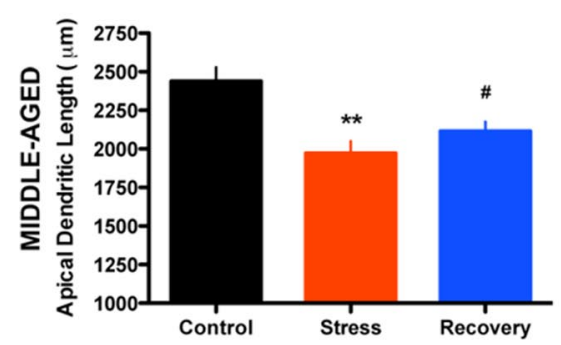

G

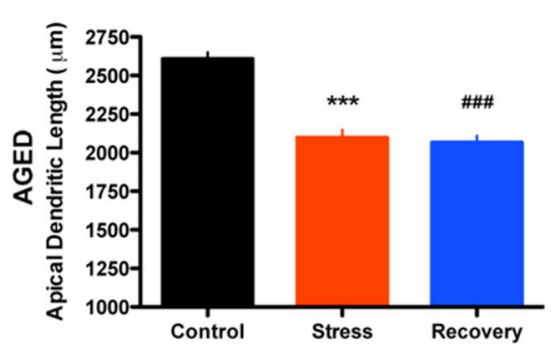

B

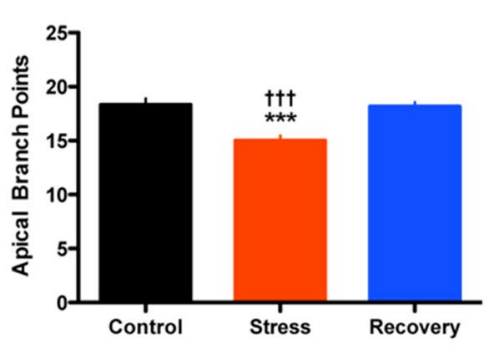

E

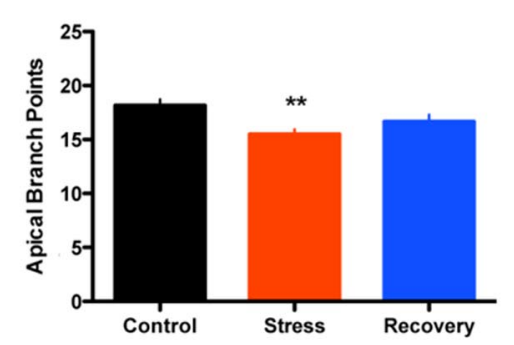

H

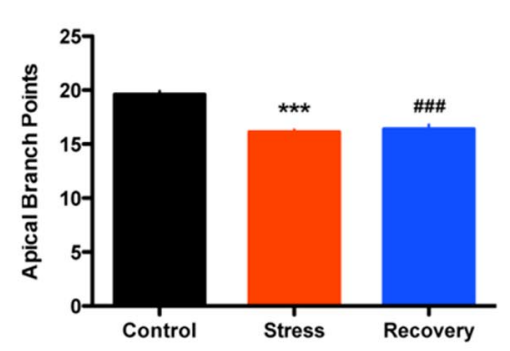

C

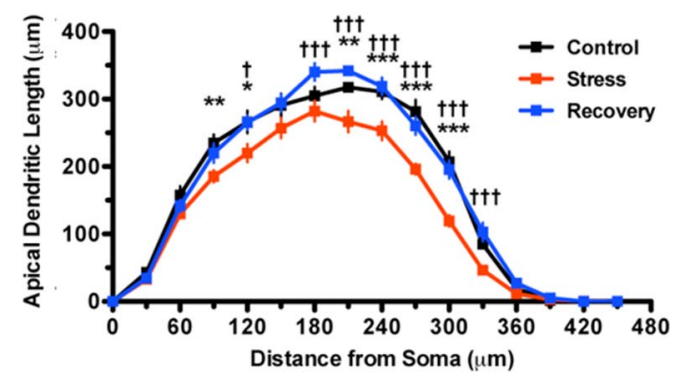

F

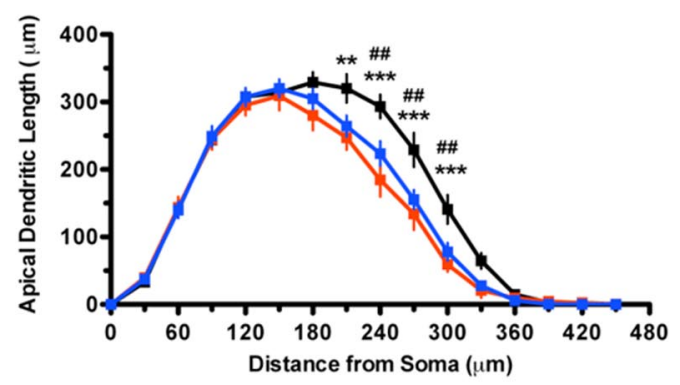

I

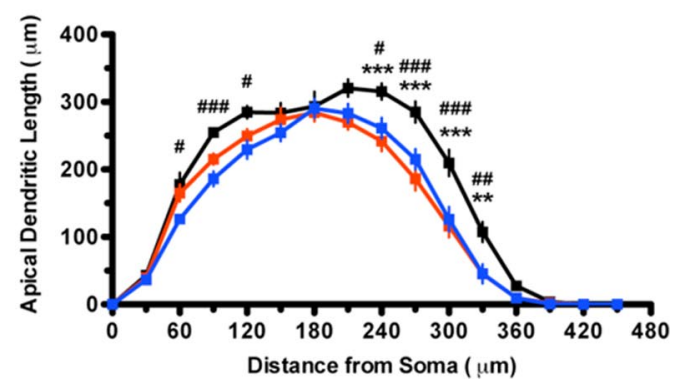

Figure 3. Aging reduces the capacity for reversible apical dendritic remodeling in response to stress. $\boldsymbol{A}-\boldsymbol{C}$, Stress caused alterations in apical dendritic morphology that were entirely reversible with recovery in young rats. $\mathbf{D}-\boldsymbol{F}$, Stress caused alterations in apical dendritic morphology that were only partially reversible with recovery in middle-aged rats. $\mathbf{G}-\mathbf{I}$, Stress caused alterations in apical dendritic morphology that were not reversible with recovery in aged rats. ${ }^{*} p<0.05$; ${ }^{* *} p<0.01$; and ${ }^{* * *} p<0.001$, control versus stress. ${ }^{\dagger} p<0.05$ and ${ }^{\text {t+t }} p<0.001$, stress versus recovery. ${ }^{\#} p<$ 0.05 ; ${ }^{\# \#} p 0.01$; and ${ }^{\# \#} p<0.001$, control versus recovery. Data presented represent group mean \pm SEM.

main effect on apical branch points $\left(F_{(2,20)}=14.86, p<0.0005\right)$, and a decrease in branch points in the stress condition compared with control and recovery (Fig. $3 B$ ). Sholl analysis revealed a significant main effect of condition $\left(F_{(2,300)}=54.64, p<0.0001\right)$ and distance from soma $\left(F_{(15,300)}=478.9, p<0.0001\right)$, and a significant interaction $\left(F_{(30,300)}=3.302, p<0.0001\right)$. Specifically, we found shorter apical dendritic lengths in stress animals compared with controls at distances of 90 and $120 \mu \mathrm{m}$, and 210-300 $\mu \mathrm{m}$, and shorter apical dendritic lengths in stress animals compared with recovery animals at distances of $120 \mu \mathrm{m}$ and 180-330 $\mu \mathrm{m}$ (Fig. 3C).

Middle-aged animals (12 months)

A total of 23 animals ( $n=7-8$ per condition) had optimal perfusions, and $142 \mathrm{PL}$ neurons were suitable for use for neural 
reconstructions (range $=5-11$, mean $=6.2$ neurons per animal). We found a main effect of condition on total apical dendritic length $\left(F_{(2,22)}=9.477, p<0.005\right)$, and a decrease in both stress and recovery animals compared with controls (Fig. $3 D)$. We also found a main effect on apical branch points $\left(F_{(2,22)}=6.345, p<\right.$ 0.01 ), and a decrease in the stress compared with controls (Fig. $3 E$ ). Sholl analysis revealed a main effect of condition $\left(F_{(2,300)}=9.39, p<\right.$ $0.005)$ and of radial distance from soma $\left(F_{(15,300)}=291.62, p<\right.$ $0.0001)$, and a significant interaction $\left(F_{(30,300)}=2.729, p<0.0001\right)$. Specifically, we found shorter apical dendritic lengths in stress animals compared with controls at distances of 210-300 $\mu \mathrm{m}$, and shorter apical dendritic lengths in recovery animals compared with controls at distances of $240-300 \mu \mathrm{m}$ (Fig. $3 F$ ).

\section{Aged animals (20 months)}

A total of 22 animals ( $n=7-8$ per condition) had optimal perfusions, and $172 \mathrm{PL}$ neurons were suitable for use for neural reconstructions (range $=5-11$, mean $=7.8$ neurons per animal). We found a main effect of condition on apical dendritic length $\left(F_{(2,21)}=41.37, p<0.0001\right)$, and decreases in both stress and recovery animals compared with controls (Fig. $3 G$ ). We also found a main effect on apical branch points $\left(F_{(2,21)}=36.19, p<\right.$ $0.0001)$, and decreases in both stress and recovery animals compared with controls (Fig. $3 H$ ). Sholl analysis revealed a main effect of condition $\left(F_{(2,266)}=41.36, p<0.0001\right)$ and radial distance from soma $\left(F_{(14,266)}=312.4, p<0.0001\right.$ : Fig. $\left.3 I\right)$, and a significant interaction $\left(F_{(28,266)}=2.957, p<0.0001\right)$. Specifically, we found shorter apical dendritic lengths between stress animals compared with controls at 240-330 $\mu \mathrm{m}$, and shorter apical dendritic lengths in recovery animals compared with controls at $60-120 \mu \mathrm{m}$ and $240-330 \mu \mathrm{m}$ (Fig. 3H).

\section{Effects of CRS and recovery on prefrontal basal dendritic morphology across ages}

Examination of the mean basal dendritic tree length revealed no main effects of condition in young rats, middle-aged rats, or aged rats (data not shown).

\section{Effects of aging on prefrontal dendritic morphology}

We examined whether age induced any significant changes in apical or basal dendritic morphology in our control animals. We found no differences among the three ages with respect to mean apical dendritic length and apical branch points (data not shown). In contrast, we found a main effect of age on basal dendrites $\left(F_{(2,21)}=4.51, p<0.05\right)$, with higher mean basal dendritic length in aged controls compared with young controls (data not shown).

\section{Discussion}

These data provide the first evidence to link aging with a selective failure of structural plasticity mechanisms in response to chronic stress. In particular, we show that while rats of all ages demonstrate stress-induced retraction in layer III mPFC neurons, aged rats demonstrated a selective and profound loss of recoveryrelated neuronal morphological resilience. This effect is also manifest in middle-aged rats, in which apical dendrites from recovery animals remained significantly shorter than those of agematched controls. In contrast to these effects, we found that dendritic morphology is remarkably stable across these ages in control animals. Interestingly, the magnitude of the morphological stress effect (i.e., 20\% apical dendritic atrophy) and its selectivity for certain portions of the apical tree remain similar across all ages. Further analysis found no lateralization of these effects; that is, remodeling at each age occurred in both right and left hemispheres to a similar extent (data not shown).

The data presented here corroborate previous reports of reversible stress-induced remodeling in PL dendrites and the selectivity of stress effects on apical, but not basal dendritic morphology (Radley et al., 2004, 2005; Dias-Ferreira et al., 2009). Similar patterns of remodeling have been correlated with selective impairments in prefrontal tasks (Liston et al., 2006). While not necessarily causally linked, these neuroanatomical observations suggest stress-induced prefrontal impairments may be related to alterations in corticocortical circuitry. A large majority of layer III neurons are corticocortically projecting neurons, and PL neurons receive dense inputs from forebrain association and parahippocampal cortices (Hoover and Vertes, 2007). The remodeling of apical branches could also have effects on the balance of excitatory drive between apical and basilar axospinous inputs, which may further disrupt connectivity to downstream mPFC targets.

Furthermore, selective remodeling within the apical tree (i.e., $210 \mu \mathrm{m}$ through $330 \mu \mathrm{m}$ ) might also be a function of the distinct neuromodulatory inputs to that apical domain. It appears this is the case for layer $\mathrm{V}$ mPFC neurons, where stress-induced atrophy has been reported to reduce EPSPs mediated by cortical serotonergic and hypocretin systems (Liu and Aghajanian, 2008). We hypothesize this may also be the case for noradrenergic inputs, which are densest in layer I and may drive some of the molecular pathways involved in stress-induced behavioral and morphological plasticity (Arnsten, 2009; Hains et al., 2009).

The major finding of this study is that age selectively impairs the ability of mPFC neurons to reversibly remodel after stress exposure. Furthermore, we found that this reduction in plasticity is evident in rats as early as middle-age. Such a compromise in plasticity may be functionally relevant, as impairments in mPFCmediated behavioral tasks have been observed in middle-aged rats, NHPs, and humans (Frick et al., 1995; Moore et al., 2006; Salthouse, 2009). Aged rats, however, demonstrate a much more profound loss of dendritic resilience in response to stress. From these data, one could speculate that stress-related and age-related functional impairments could be additive and irreversible. Surprisingly, we found few changes in layer III PL neuronal morphology with relation to aging, which is consistent with a recent study that found no effect of age on dendritic morphology in behaviorally impaired rats (Brennan et al., 2009), but contrasts with a previous study that found reductions in layer III dendritic complexity with age (Grill and Riddle, 2002). It remains possible that alterations in the number, size, and molecular composition of PL axospinous synapses could explain functional impairments with aging.

We find here that stress increases adrenal gland weight at all ages, consistent with the idea that chronic elevation of adrenal gland hormones, including glucocorticoids (GCs), is a mediator of neuronal remodeling. GCs, while sufficient to cause hippocampal CA3 and mPFC remodeling that mimics the stressed condition (Watanabe et al., 1992b; Wellman, 2001), appear to require activation of $N$-methyl-D-aspartate receptors (Magariños and McEwen, 1995). GCs mediate glutamate release in response to stress (Moghaddam et al., 1994), and aged rats display a protracted GC and glutamate response to stress (Sapolsky et al., 1983; Lowy et al., 1995). Furthermore, recent work has demonstrated that stress-induced remodeling requires neuropeptides such as brain derived neurotrophic factor and tissue plasminogen activator (Pawlak et al., 2005; Magarinos et al., 2010); thus stressinduced GCs may be best viewed as permissive mediators 
working in conjunction with additional molecules to cause stress-induced structural remodeling. The molecular pathways that underlie recovery-related morphological resilience in young animals, and how they may be impaired with aging, remain unknown.

The current results provide a framework for future studies that should be aimed at understanding further the mechanism and significance of loss of resilience in the aging brain. The loss of resilience seen with age here may have relevance to human disease, as features of psychiatric disorders such as posttraumatic stress disorder and depression can be ascribed to impairments in resilience to stressful experience (Nesse, 2000; Feder et al., 2009). To what extent the stress-aging-recovery interaction can be generalized to other stress-sensitive brain regions, such as hippocampus and amygdala, is unknown. There is good reason to anticipate similar findings in hippocampal CA3 neurons, which exhibit apical dendritic retraction with chronic stress in a reversible manner (Conrad et al., 1999), but opposite findings in basolateral amygdala neurons, where stress has been shown to cause dendritic hypertrophy which fails to reverse with recovery (Vyas et al., 2004).

Future studies within the prefrontal cortex should investigate the behavioral ramifications of the interaction of stress and aging, as well as identify mechanisms to increase recovery-related plasticity in aging neurons. Several studies have demonstrated a link between morphological recovery from stress and normalization of cognitive behaviors (Sousa et al., 2000), including dorsolateral PFC connectivity and set-shifting performance in humans (Liston et al., 2009). Manipulations including environmental enrichment and exercise have been reported to be neuroprotective in the aging brain and may aid in resilience in aging rodents (Cotman and Berchtold, 2002; Segovia et al., 2009) and humans (Colcombe et al., 2004; Carlson et al., 2009). Similarly, examining the molecular mechanisms of recovery-related plasticity that are impaired in the aging brain may lead to pharmacological targets that ameliorate age-related cognitive decline and perhaps neurodegenerative disease such as $\mathrm{AD}$.

\section{References}

Arnsten AF (2009) Stress signalling pathways that impair prefrontal cortex structure and function. Nat Rev Neurosci 10:410-422.

Barense MD, Fox MT, Baxter MG (2002) Aged rats are impaired on an attentional set-shifting task sensitive to medial frontal cortex damage in young rats. Learn Mem 9:191-201.

Brennan AR, Yuan P, Dickstein DL, Rocher AB, Hof PR, Manji H, Arnsten AF (2009) Protein kinase C activity is associated with prefrontal cortical decline in aging. Neurobiol Aging 30:782-792.

Burke SN, Barnes CA (2006) Neural plasticity in the ageing brain. Nat Rev Neurosci 7:30-40.

Carlson MC, Erickson KI, Kramer AF, Voss MW, Bolea N, Mielke M, McGill S, Rebok GW, Seeman T, Fried LP (2009) Evidence for neurocognitive plasticity in at-risk older adults: the experience corps program. J Gerontol A Biol Sci Med Sci 64:1275-1282.

Colcombe SJ, Kramer AF, Erickson KI, Scalf P, McAuley E, Cohen NJ, Webb A, Jerome GJ, Marquez DX, Elavsky S (2004) Cardiovascular fitness, cortical plasticity, and aging. Proc Natl Acad Sci U S A 101:3316-3321.

Conrad CD, LeDoux JE, Magariños AM, McEwen BS (1999) Repeated restraint stress facilitates fear conditioning independently of causing hippocampal CA3 dendritic atrophy. Behav Neurosci 113:902-913.

Cotman CW, Berchtold NC (2002) Exercise: a behavioral intervention to enhance brain health and plasticity. Trends Neurosci 25:295-301.

Dias-Ferreira E, Sousa JC, Melo I, Morgado P, Mesquita AR, Cerqueira JJ, Costa RM, Sousa N (2009) Chronic stress causes frontostriatal reorganization and affects decision-making. Science 325:621-625.

Dickstein DL, Kabaso D, Rocher AB, Luebke JI, Wearne SL, Hof PR (2007) Changes in the structural complexity of the aged brain. Aging Cell 6:275-284.
Feder A, Nestler EJ, Charney DS (2009) Psychobiology and molecular genetics of resilience. Nat Rev Neurosci 10:446-457.

Frick KM, Baxter MG, Markowska AL, Olton DS, Price DL (1995) Agerelated spatial reference and working memory deficits assessed in the water maze. Neurobiol Aging 16:149-160.

Gallagher M, Rapp PR (1997) The use of animal models to study the effects of aging on cognition. Annu Rev Psychol 48:339-370.

Grady CL (2008) Cognitive neuroscience of aging. Ann NY Acad Sci 1124:127-144.

Grill JD, Riddle DR (2002) Age-related and laminar-specific dendritic changes in the medial frontal cortex of the rat. Brain Res 937:8-21.

Hains AB, Vu MA, Maciejewski PK, van Dyck CH, Gottron M, Arnsten AF (2009) Inhibition of protein kinase C signaling protects prefrontal cortex dendritic spines and cognition from the effects of chronic stress. Proc Natl Acad Sci U S A

Hof PR, Morrison JH (2004) The aging brain: morphomolecular senescence of cortical circuits. Trends Neurosci 27:607-613.

Hoover WB, Vertes RP (2007) Anatomical analysis of afferent projections to the medial prefrontal cortex in the rat. Brain Struct Funct 212:149-179.

Liston C, Miller MM, Goldwater DS, Radley JJ, Rocher AB, Hof PR, Morrison JH, McEwen BS (2006) Stress-induced alterations in prefrontal cortical dendritic morphology predict selective impairments in perceptual attentional set-shifting. J Neurosci 26:7870-7874.

Liston C, McEwen BS, Casey BJ (2009) Psychosocial stress reversibly disrupts prefrontal processing and attentional control. Proc Natl Acad Sci U S A 106:912-917.

Liu RJ, Aghajanian GK (2008) Stress blunts serotonin- and hypocretinevoked EPSCs in prefrontal cortex: role of corticosterone-mediated apical dendritic atrophy. Proc Natl Acad Sci U S A 105:359-364.

Lowy MT, Wittenberg L, Yamamoto BK (1995) Effect of acute stress on hippocampal glutamate levels and spectrin proteolysis in young and aged rats. J Neurochem 65:268-274.

Lupien SJ, McEwen BS, Gunnar MR, Heim C (2009) Effects of stress throughout the lifespan on the brain, behaviour and cognition. Nat Rev Neurosci 10:434-445.

Magariños AM, McEwen BS (1995) Stress-induced atrophy of apical dendrites of hippocampal CA3c neurons: involvement of glucocorticoid secretion and excitatory amino acid receptors. Neuroscience 69:89-98.

Magarinos AM, Li CJ, Toth JG, Bath KG, Jing D, Lee FS, McEwen BS (2010) Effect of brain-derived neurotrophic factor haploinsufficiency on stressinduced remodeling of hippocampal neurons. Hippocampus. Advance online publication. Retrieved February 1, 2010. doi:10.1002/hipo.20744.

Miller EK, Freedman DJ, Wallis JD (2002) The prefrontal cortex: categories, concepts and cognition. Philos Trans R Soc Lond B Biol Sci 357:1123-1136.

Moghaddam B, Bolinao ML, Stein-Behrens B, Sapolsky R (1994) Glucocorticoids mediate the stress-induced extracellular accumulation of glutamate. Brain Res 655:251-254.

Moore TL, Killiany RJ, Herndon JG, Rosene DL, Moss MB (2006) Executive system dysfunction occurs as early as middle-age in the rhesus monkey. Neurobiol Aging 27:1484-1493.

Morrison JH, Hof PR (1997) Life and death of neurons in the aging brain. Science 278:412-419.

Nesse RM (2000) Is depression an adaptation? Arch Gen Psychiatry 57:14-20.

Pawlak R, Rao BS, Melchor JP, Chattarji S, McEwen B, Strickland S (2005) Tissue plasminogen activator and plasminogen mediate stress-induced decline of neuronal and cognitive functions in the mouse hippocampus. Proc Natl Acad Sci U S A 102:18201-18206.

Paxinos G, Watson C (2005) The rat brain in stereotaxic coordinates, Ed 5. San Diego: Elsevier.

Radley JJ, Sisti HM, Hao J, Rocher AB, McCall T, Hof PR, McEwen BS, Morrison JH (2004) Chronic behavioral stress induces apical dendritic reorganization in pyramidal neurons of the medial prefrontal cortex. Neuroscience 125:1-6.

Radley JJ, Rocher AB, Janssen WG, Hof PR, McEwen BS, Morrison JH (2005) Reversibility of apical dendritic retraction in the rat medial prefrontal cortex following repeated stress. Exp Neurol 196:199-203.

Radley JJ, Rocher AB, Miller M, Janssen WG, Liston C, Hof PR, McEwen BS, Morrison JH (2006) Repeated stress induces dendritic spine loss in the rat medial prefrontal cortex. Cereb Cortex 16:313-320.

Rapp PR, Gallagher M (1996) Preserved neuron number in the hippocam- 
pus of aged rats with spatial learning deficits. Proc Natl Acad Sci U S A 93:9926-9930.

Salthouse TA (2009) When does age-related cognitive decline begin? Neurobiol Aging 30:507-514.

Sapolsky RM (1999) Glucocorticoids, stress, and their adverse neurological effects: relevance to aging. Exp Gerontol 34:721-732.

Sapolsky RM, Krey LC, McEwen BS (1983) The adrenocortical stressresponse in the aged male rat: impairment of recovery from stress. Exp Gerontol 18:55-64.

Segovia G, del Arco A, Mora F (2009) Environmental enrichment, prefrontal cortex, stress, and aging of the brain. J Neural Transm 116:1007-1016.

Sousa N, Lukoyanov NV, Madeira MD, Almeida OF, Paula-Barbosa MM (2000) Reorganization of the morphology of hippocampal neurites and synapses after stress-induced damage correlates with behavioral improvement. Neuroscience 97:253-266.

Vyas A, Pillai AG, Chattarji S (2004) Recovery after chronic stress fails to reverse amygdaloid neuronal hypertrophy and enhanced anxiety-like behavior. Neuroscience 128:667-673.

Watanabe Y, Gould E, McEwen BS (1992a) Stress induces atrophy of apical dendrites of hippocampal CA3 pyramidal neurons. Brain Res 588:341-345.

Watanabe Y, Gould E, Cameron HA, Daniels DC, McEwen BS (1992b) Phenytoin prevents stress- and corticosterone-induced atrophy of CA3 pyramidal neurons. Hippocampus 2:431-435.

Wellman CL (2001) Dendritic reorganization in pyramidal neurons in medial prefrontal cortex after chronic corticosterone administration. J Neurobiol 49:245-253. 